\title{
A implantação dos currículos de Educação Física da UFRGS em 2012: uma visão dos estudantes em transição curricular
}

\author{
Implementation of Physical Education curriculum at UFRGS in 2012 : \\ vision of students in curricular transition
}

\section{Priscila Furtado Limana', Eduardo Pinto Machado', Alex Branco Fraga}

'Universidade Federal do Rio Grande do Sul (ESEFID/UFRGS)

Recebido em: 31/03/2016 / Aceito em: 11/05/2016

eduardo.machado@ufrgs.br

\section{RESUMO}

Em 2012, os cursos de Educação Física da Universidade Federal do Rio Grande do Sul (UFRGS) passaram por uma reestruturação curricular. Foi um período de dúvidas e reflexões em torno das mudanças que estavam ocorrendo, principalmente para os estudantes que ingressaram no currículo "antigo". Para tanto, visamos verificar os relatos dos estudantes que vivenciaram o processo de transição curricular dos cursos de Educação Física da UFRGS, utilizando o documento produzido pelo Núcleo de Avaliação da Unidade (NAU) em 2012, sobre a avaliação da implantação dos novos currículos da Educação Física da UFRGS. Objetivo: por meio da análise destes dados dos relatórios do NAU, buscou-se identificar como os estudantes do currículo "antigo" perceberam a mudança de currículo em 2012 e quais eram os aspectos negativos e positivos dos novos currículos dos cursos de Licenciatura e Bacharelado em Educação Física da UFRGS. Método: trata-se de uma investigação de natureza qualitativa que se valeu da análise de documentos, neste caso, dos relatórios produzidos pelo NAU: Avaliação da Implantação do Novo Currículo dos Cursos de Educação Física (dezembro 2012) e Avaliação dos Cursos de Dança, Fisioterapia e Educação Física (abril 2012). Considerações finais: os relatos dos estudantes em transição curricular mostraram que a implantação do "novo" currículo foi percebida de modo mais negativo do que positivo, principalmente pelo fato de que as alterações curriculares levaram a grande maioria dos estudantes em transição curricular ao adiamento da conclusão do curso. Por isso, recomendamos que em processos similares, futuramente, sejam adotadas medidas de transição curricular que minimizem os efeitos negativos observados ao longo da reestruturação na ESEFID.

Palavras-chave: Currículo; Avaliação Educacional; Educação Física; Educação Superior.

\section{ABSTRACT}

In 2012 the Physical Education degrees of Federal University of Rio Grande do Sul (UFRGS) went through a curricular reorganization. It was a period of doubts and reflections around the current changes, especially to those students admitted under the "old" course structure. Objective: therefore, we aim to verify the narrative of students who experienced the curricular transition process, using the evaluation document of the new deployment curriculum produced by the "Núcleo de Avaliação da Unidade" (Evaluation Unit Core - NAU) in 2012. Through the analysis of the NAU report data, we seek to identify how the students of the "old" curriculum realized the curriculum change in 2012 and what were the negative and positive aspects of the new curriculum of Physical Education courses at UFRGS. Method: this is a qualitative investigation based on the analysis of documents, in this case, NAU's report: Analysis of the New Course Structure Implementation on the Physical Education degree (December, 2012) and Analysis of the Dance, Physiotherapy and Physical Education Course Structure (April, 2012). Closing remarks: reports from students in curricular transition showed that the implementation of the "new" curriculum was perceived more negatively than positive, especially the fact that 
the curriculum changes have led the vast majority of students in curricular transition to the postponement of graduation. Therefore, we recommend that in similar cases in future curricular transition measures are taken to minimize the negative effects observed during the restructuring at Physical Education courses.

Keywords: Curriculum; Educational Measurement; Physical Education; College.

\section{INTRODUÇÃO}

Em 2012, os cursos de Educação Física da Universidade Federal do Rio Grande do Sul (UFRGS) passaram por uma reestruturação curricular. Após ampla discussão entre a comunidade acadêmica e aprovação nas instâncias internas da UFRGS, ficou decidido que os estudantes ingressariam via vestibular na Licenciatura em Educação Física e, após concluí-la, teriam direito a pedir permanência, mecanismo que Ihes permitiria ingressar no curso de Bacharelado em Educação Física. Consta no Projeto Pedagógico dos Cursos de Educação Física que, após o término da Licenciatura, o estudante está apto a solicitar a permanência para o Bacharelado em Educação Física, de forma a cursar as disciplinas específicas do currículo para concluir esta segunda formação. ${ }^{1}$ Dessa forma, os estudantes da graduação teriam a opção de uma dupla formação que lhes permitiria atuar tanto nos espaços escolares (Licenciado) quanto no espaços extra-escolares (Bacharel) sem contrariar a legislação (ou interpretações sobre a legislação) no que se refere ao exercício profissional em Educação Física.

Todos os ingressantes no curso de Educação Física da UFRGS até o ano de 2011, que estavam com matrícula ativa à época da reestruturação dos cursos, passaram por essa adaptação curricular. Foi um período de turbulência para a comunidade da ESEFID/UFRGS, pois surgiram diversas dúvidas sobre como transcorreria esta transição curricular, houve ruídos na comunicação entre os setores responsáveis e conflitos entre discentes e docentes em função de expectativas, de um e de outro segmento, não terem sido atendidas.

Nesse mesmo ano da mudança, o Núcleo de Avaliação da Unidade (NAU) da ESEFID/UFRGS realizou duas pesquisas ${ }^{* 1}$ com os estudantes de Educação Física: a primeira pesquisa, foi oriunda da Terceira Etapa de Avaliação do NAU, considerou o momento de reestruturação curricular iniciado em 2010 nos cursos de Educação Física. Nessa etapa, o NAU avaliou os cursos oferecidos pela ESEF/UFRGS, sobretudo no que se refere aos aspectos físicos, recursos humanos e o currículo desenvolvido a partir da estrutura vigente. ${ }^{2,3}$ E a segunda pesquisa, correspondia à Quarta Etapa de Trabalho do NAU/ESEFID, intitulada "Avaliação da Implantação do Novo Currículo dos Cursos de Educação Física", tratou de analisar o processo de reestruturação curricular dos cursos de Educação Física da UFRGS. ${ }^{3}$
Nesta etapa de trabalho, o NAU utilizou os seguintes procedimentos metodológicos: a) escolha dos temas a serem incluídos nas etapas avaliativas; b) aplicação de questionários dirigidos a estudantes e professores da ESEFID; c) grupos focais com intuito de aprofundar qualitativamente os temas. Estes grupos focais foram montados de acordo com os segmentos aos quais os participantes faziam parte: estudantes, professores ou coordenadores. E por haver grande diferença na trajetória do curso entre as turmas de ingressantes no novo currículo e as turmas de remanescentes do currículo "antigo", o NAU construiu instrumentos específicos para captar a percepção sobre as alterações propostas pelos grupos de estudantes do currículo "antigo", de ingressantes e de professores.

Consideramos que um estudo dessa natureza se justifica pelo fato de oferecer subsídios para a adoção de medidas de transição curricular que minimizem os efeitos negativos observados ao longo deste processo. Para tanto, analisamos os dados obtidos no ano de 2012 pelo NAU/ESEFID da UFRGS ${ }^{2,3}$ e, a partir dessas informações, realizamos uma discussão sob a luz da literatura que versa sobre a construção curricular no Ensino Superior, da reestruturação curricular e da formação de professores. Levando em consideração tal relevância, o objetivo deste estudo consistiu em compreender, mais especificamente, os relatos deixados pelos estudantes em transição curricular nos relatórios do NAU de forma a identificar como esses estudantes perceberam as mudanças curriculares.

Esse trabalho está baseado na concepção de análise documental de Laurence Bardin ${ }^{4}$ e de André Cellard. ${ }^{5}$ A análise documental de caráter qualitativo, para Cellard, ${ }^{5}$ permite ao pesquisador acrescentar a dimensão do tempo à compreensão social. Além disso, aconselha ao pesquisador que trabalha com documentos alguns cuidados antes de analisar em profundidade o material como: consultar trabalhos de outros pesquisadores que trabalham com objetos de estudo semelhantes, não se precipitar sobre o primeiro conjunto de documentos encontrados e esgotar todas as pistas possíveis em busca de informações. ${ }^{5}$

Para o processo de coleta de informações foi realizada uma busca aos relatórios disponíveis na Biblioteca Edgar Sperb, localizada na ESEFID/UFRGS; nos sites da Secretaria de Avaliação Institucional (SAI) e do NAU da ESEFID/UFRGS. No intuito de acrescentar dados à empiria, os autores mantiveram um diálogo com integrantes do NAU para fins de esclarecimentos sobre como foram realizados os processos avaliativos dos relatórios analisados. A varredura documental fez-nos obter dois relatórios, que consistiram nos seguintes documentos brutos realizados pelo NAU da ESEFID/UFRGS: i) Avaliação da Implantação do Novo Currículo dos Cursos de Educação Física; ${ }^{2}$ e ii) Avaliação dos Cursos de Dança, Fisioterapia e Educação Física, ambos do ano de 2012. ${ }^{3}$

Esses documentos descreviam, entre outros aspectos, a perspectiva dos estudantes em transição

\footnotetext{
* 1: A Primeira Etapa de Trabalho do NAU/ESEFID ocorreu no período de março a maio de 2009, onde o Núcleo mapeou os diferentes setores cursos, recursos físicos, recursos humanos e interfaces estabelecidas no ambiente da ESEFID. A Segunda Etapa consistiu em um levantamento qualitativo, realizado no período de junho de 2009 a junho de 2010, visando dar voz às pessoas que trabalhavam na Unidade (ESEFID) em seus diversos segmentos e funções variadas. Essas duas etapas iniciais não fazem parte desse estudo.
} 
curricular, dados sobre a implantação do novo currículo nos cursos de Educação Física da UFRGS, em 2012, além dos perfis destes estudantes ingressos do currículo "antigo". Desses documentos foram extraídos apenas os relatos dos estudantes sobre a implantação do novo currículo na ESEFID/UFRGS, especialmente em relação às ponderações caracterizadas pelos discentes como positivas e negativas acerca desse processo. A partir disso, as respostas foram agrupadas conforme a semeIhança entre os assuntos, de modo que as respostas que se distanciavam dos temas "currículo novo", "currículo", "estudantes do currículo antigo", "estudantes em transição curricular", não foram computadas aos resultados do presente estudo.

\section{Currículos de Formação Superior em Educação Física da ESEFID/UFRGS}

Tratando-se de currículo, muitas são as compreensões e concepções acerca deste tema. O marco teórico-conceitual que orientou as discussões sobre esta temática nesse estudo se baseou, de um modo mais geral, nas teorizações de José Gimeno Sacristán. ${ }^{6}$ Para Sacristán, é difícil ordenar num esquema e num único discurso coerente todas as funções e formas que parcialmente um currículo pode adotar. ${ }^{6}$ Para o autor, quando definimos currículo estamos descrevendo a forma particular das funções da instituição de ensino num momento histórico e social determinado. ${ }^{6}$ Sacristán indica, também, dois grupos de significados sobre currículo: um primeiro que considera o currículo como um guia da experiência que o aluno obtém na escola; um segundo que define currículo como o conjunto de conteúdos estabelecidos para a educação. Sendo assim, o currículo deve ser entendido como uma prática social concreta e não um objeto estático, um modelo pré-determinado de organização das trajetórias de aprendizagem tidas como necessárias aos estudantes de um dado nível de ensino. ${ }^{6}$

Adotando a perspectiva do currículo tal como proposta por Sacristán, ${ }^{6}$ passamos a sustentar a investigação sobre currículo no âmbito do ensino superior em estudos provenientes do campo da Educação Física. Neste ponto, cabe destacar três trabalhos: um é o de Fábio Brugnerotto e Regina Simões, ${ }^{7}$ que analisa o conceito de saúde nos currículos de doze cursos de formação em Educação Física das principais universidades do Estado do Paraná correlacionando com as concepções teóricas das diretrizes nacionais para os cursos de graduação em saúde. Estes autores identificaram que, apesar de as diretrizes fomentarem a produção de currículos alinhados à perspectiva da saúde pública e os princípios da promoção da saúde, a perspectiva biomédica era ainda predominante. ${ }^{7} \mathrm{O}$ segundo é o trabalho de Cláudio Lúcio Mendes, ${ }^{8}$ que fez uma revisão de literatura com 20 artigos encontrados em revistas e periódicos de circulação nacional publicados no período de 1987 a 1996 sobre o tema currículo do Ensino Superior de Educação Física, apontando em conclusão para a necessidade de se investir em estudos que tratem das relações entre as disciplinas teóricas e práticas na organização dos currículos da área. ${ }^{8} \mathrm{O}$ terceiro é o artigo de Alex Fraga e colegas, ${ }^{9}$ pois trata de analisar as alterações curriculares mais marcantes entre os anos de 1941 e 2010 dos cursos de Educação Física da ESEFID. ${ }^{9}$

A ESEFID/UFRGS como instituição de ensino possui uma história curricular importante na formação de profissionais da Educação Física, com destaque para três momentos marcantes: a federalização da escola em 1970; mudanças curriculares em 1987 e a divisão da licenciatura e bacharelado em 2005..$^{9}$ Além disso, em 2010, uma nova reestruturação curricular se mostrou mais um marco nesta história, pois foi o ano em que a comunidade esefidiana definiu as linhas gerais de um novo currículo para os cursos de formação superior em Educação Física da Unidade, baseado em um princípio básico: um currículo unificado, que permitisse a dupla modalidade de formação (licenciatura/bacharelado) em um curso único de Educação Física. ${ }^{9}$

Com o início dos processos de alterações curriculares, a implantação do novo currículo estava prevista já para o ano de 2012. Essa mobilização surgiu de um conjunto de fatores gerados a partir, principalmente, da inconformidade de boa parte da comunidade da ESEFID com a estrutura curricular vigente na época e com a discriminação das habilitações para o exercício profissional imposta pela determinação do Conselho Federal de Educação Física, por ocasião da Lei n. 9696/1998, que regulamentou a profissão de Educação Física. ${ }^{10}$ Enquanto nas alterações curriculares de 1987 a escola passou quase dez anos discutindo a estrutura curricular mais adequada ao perfil do egresso estipulado, em 2004, no segundo caso, não chegou a dois anos de discussão, o que levou a formulação de currículos sem um amplo respaldo interno; restrito às adequações da grade que já se tinha à época para a licenciatura ampliada às diretrizes curriculares vigentes. ${ }^{9}$ Logo os sinais do desgaste vieram à tona e a comunidade da ESEFID começava a colocar em pauta o atual ordenamento curricular, estimulando a reestruturação de 2012 .

Como citado, as mudanças aconteceram rapidamente, e o NAU da ESEFID/UFRGS se valeu do momento para uma avaliação dos currículos e dos cursos oferecidos no campus Olímpico da UFRGS, verificando de que forma as mudanças afetariam os diversos estudantes e alguns setores da instituição.

\section{Os Relatórios de Avaliação do NAU}

O relatório parcial "Avaliação do Currículo dos Cursos de Dança, Fisioterapia e Educação Física" de abril de 2012, consiste em um documento que apresenta a terceira etapa de trabalho do NAU, realizado no período de julho de 2010 a julho de 2011. Foram respondidos 331 questionários por parte dos alunos da Licenciatura em Educação Física e 320 questionários pelos estudantes do Bacharelado em Educação Física. O modo de ingresso predominante entre os participantes do estudo foi via vestibular, acesso universal ou sistema de cotas. ${ }^{2}$

Na Licenciatura em Educação Física, os estudantes participantes ingressaram no curso entre os anos de 2002 e 2010, sendo que a maior parte deles era ingressante do ano de 2010. Dos 331 questionários respondidos pelos estudantes da Licenciatura, 40 destes estudantes passaram a informação de que o estudante já havia iniciado outro curso antes; do total de participantes, $57 \%$ haviam cursado o Ensino Médio em escolas da rede pública e tinham entre 18 e 24 anos de idade. ${ }^{2}$ 
No curso de Bacharelado em Educação Física, os 320 estudantes participantes ingressaram no curso entre os anos de 2002 e 2010, sendo que a maior parte deles era ingressante dos anos de 2009 e 2010; do total de participantes, 44 dos estudantes já haviam iniciado outro curso antes; mais da metade dos estudantes do Bacharelado em Educação Física que respondeu ao questionário indicou que havia cursado o Ensino Médio em escolas da rede privada e tinham entre 18 e 23 anos de idade. ${ }^{2}$

\section{DISCUS5ÃO}

A discussão a seguir enfatizou os aspectos considerados mais relevantes a partir dos relatórios do NAU acerca dos estudantes em transição curricular. Foi possível caracterizar, a partir dos achados documentais, duas categorias analíticas: a primeira abordando os impactos iniciais referentes às mudanças curriculares percebidas pelos estudantes do currículo "antigo", e a segunda acerca das polaridades existentes no currículo implantado em 2012.

\section{Estudantes em Transição Curricular e as Primeiras Im-} pressões da Reestruturação Curricular

A partir dos documentos prospectados foi possível observar algumas questões que merecem destaque: o currículo vigente até 2011 já vinha sendo questionado pelo segmento dos estudantes. Dentre os fatores de descontentamento, estudos anteriores apresentam indícios de que havia uma possível insatisfação com o currículo anterior pelo fato que ele era composto por uma grade de disciplinas distribuída durante o dia inteiro, sem separações por turnos específicos (manhã, tarde e/ou noite), fato que dificultava as oportunidades de emprego e estágios aos estudantes. ${ }^{11}$ Ademais, no currículo "antigo" não havia disciplinas esportivas obrigatórias, sendo possível, então, que os estudantes concluíssem a graduação sem cursar disciplinas clássicas na formação da área (futebol, voleibol, basquetebol, etc.). ${ }^{* 2}$

Os questionamentos sobre repetições e similaridades de conteúdos e das avaliações foram constantes nos documentos elaborados pelo NAU/ESEFID. Também foram frequentes as falas dos estudantes indicando situações nas quais entendiam que os professores não conseguiam relacionar em suas metodologias a prática e a teoria apresentadas nos conteúdos de aula. Com achados semelhantes, em 2009, Jonas Daniel realizou um Trabalho de Conclusão de Curso (TCC) na UFRGS intitulado "O Curso de Educação Física na UFRGS: a voz discente"..$^{11} \mathrm{O}$ autor buscou relatos dos estudantes sobre o curso de Educação Física (ainda sob a tutela do currículo "antigo") e ficou evidente alguma das dificuldades dos estudantes decorrentes da estrutura curricular vigente à época, como se pode notar na citação a seguir:11

Os/as estudantes enfrentam dificuldades de articulação entre os diferentes conteúdos curriculares tratados ao longo da graduação e as necessidades concretas surgidas no âmbito da prática docente. O que pode ser compreendido, em grande parte, pela forma fragmentada que o curso organiza o conhecimento e pela maneira desarticulada que as disciplinas se apresentam. Os/as estudantes perspectivam uma concepção integradora do currículo, realçando a relação dialética existente entre a teoria e a prática, que deve estar presente em todos os momentos da formação (p.5)

Os argumentos de Jonas Daniel ${ }^{11}$ foram apresentados antes da reestruturação curricular de 2012 e nele já era possível perceber indícios dos fatos que levaram a comunidade da ESEFID a investir em mudanças curriculares instauradas em 2012. Contudo, apesar da alteração curricular na ESEFID/UFRGS ter sido ampla e detalhadamente discutida (o processo, desde sua origem, durou cerca de três anos e passou pelo crivo de diferentes comissões especiais), a implantação de todo a grade ocorreu de uma vez só e de maneira abrupta. Certamente, os danos ao percurso curricular dos estudantes teriam sido reduzidos se a implantação do novo currículo acontecesse ano a ano, a cada novo grupo de ingressantes. O ideal seria que não existisse um grupo de estudantes "em transição", mas sim um grupo pertencente a um currículo em processo de extinção. Alguns relatos mostram estudantes com dúvidas acerca da nova proposta curricular: ${ }^{3}$

Explicar melhor para todos o que está acontecendo e porque a mudança ocorreu. [...] Deveria acontecer um esclarecimento maior sobre a situação de cada aluno com o novo currículo porque todos falam ao mesmo tempo e a gente não sabe quem está falando o certo (p.70)

Os estudantes questionavam o porquê de muitas das mudanças e o motivo de não possibilitar a alteração de outros aspectos que já vinham solicitando, tais como: "por que não se poderia concluir a graduação no currículo de origem do ano de ingresso?" Ou "se houve separação em turnos manhã e tarde, qual a razão de não oferecer também o turno noite?" Estas questões eram frequentes entre os estudantes quando o assunto era a reestruturação curricular, no entanto, os docentes esclareciam as discussões expondo a falta de infraestrutura do campus e a necessidade que se teria de ampliar o corpo docente da ESEFID para comportar a demanda de tantos currículos vigentes se fossem mantidos os currículos anteriores à reestruturação de 2012. Assim, restou aos estudantes se adaptarem ao novo currículo para reduzir os atritos com os setores da ESEFID, como a Comissão de Graduação em Educação Física, que é a instância responsável pelo gerenciamento dos currículos dos Cursos de Licenciatura e Bacharelado em Educação Física, bem como pelo acompanhamento da vida acadêmica dos estudantes.

A comunidade da ESEFID passava por um momento em que alterações eram necessárias para adequar à

\footnotetext{
* 2: Tal informação pode ser verificada analisando a grade curricular implementada no ano de 2006, a qual indica a necessidade de 68 créditos eletivos para a formação do discente, mas não apresenta nenhuma disciplina esportiva "clássica" (Futebol, Futsal, Voleibol, Basquetebol) como atividade de ensino obrigatória ao percurso curricular do estudante. A grade curricular de 2006 pode ser visualizada no seguinte link: http:// www1.ufrgs.br/graduacao/xInformacoesAcademicas/curriculo.php? CodCurso $=314 \&$ CodHabilitacao $=98 \&$ CodCurriculo $=280 \&$ sem $=2006012$
} 
formação dos acadêmicos às novas demandas do campo de atuação profissional. E, neste sentido, há relatos de estudantes em transição que indicam que os aspectos positivos nas mudanças curriculares seriam sentidos, especialmente, pelos ingressantes a partir de 2012, como pode ser observado no trecho abaixo destacado: “O novo currículo é muito bom para quem entrará nele desde o início. Para quem já estava no meio do curso ficou meio confuso e atrapalhou a expectativa de se formar". (p.67). ${ }^{3}$ "Creio que as alterações do currículo deveriam funcionar e ter efeito apenas para os alunos novos" (p.71). ${ }^{3}$

Apontar que o currículo "funcionaria" para os ingressantes de 2012 em diante está diretamente relacionado às diversas dificuldades que os estudantes enfrentaram durante a transição curricular. As modificações de carga horária $(\mathrm{CH})$ nas disciplinas do currículo foram identificadas como o maior dos empecilhos na transição curricular. Por exemplo, algumas disciplinas que tinham 30 horas passaram para 60 horas, outras tinham 90 horas e reduziram para 30. Enfim, esta situação acarretou em redução de algumas disciplinas, mas também trouxe o acréscimo de outras atividades de ensino, fato que, para grande parte dos estudantes em transição curricular, acarretou na ampliação do tempo que faltava para a conclusão do curso.

Tanto no currículo "antigo", quanto no currículo implementado em 2012, o curso de Licenciatura em Educação Física da UFRGS se encontrava dividido em oito etapas, as quais correspondiam a um conjunto de disciplinas que são sugeridas para uma boa sequência no curso em um mesmo semestre letivo em direção à oitava etapa. Este sequenciamento projetava a passagem de cada estudante por um fluxo de progressão de conhecimentos necessários a sua formação acadêmica. Contudo, em 2012, o currículo reajustou disciplinas dentro dessas etapas citadas, ou seja, disciplinas que antes eram da sétima etapa, por exemplo, passaram a constituir a quarta etapa. Logo, os estudantes em transição curricular que cursaram disciplinas reajustadas nestas etapas viram seus históricos escolares, bem como seus ordenamentos ${ }^{* 3}$ dentro do curso ser alterados. O ordenamento das matrículas na UFRGS é um elemento extremamente importante para a boa progressão dentro do curso, pois é por meio deste mecanismo peculiar que cada estudante é posicionado na hora de concorrer às vagas nas disciplinas a cada semestre. Como o ordenamento classifica os estudantes em valores numéricos (mediante cálculo de índices de desempenho, obedecendo a regras determinadas), quem estiver em etapas iniciais, será contabilizado no cálculo de ordem como menos qualificado para matricular-se em disciplinas de etapas avançadas, pois como já citado anteriormente, o currículo vigente prevê um sequência de conhecimentos a serem adquiridos ao longo da graduação. Toda esta situação também acarretou aos estudantes em transição curricular o distanciamento da expectativa de término do curso.

Mais um aspecto identificado no relatório, ${ }^{3}$ e que também trazia dificuldades aos estudantes do currículo "antigo", estava relacionado às colisões de horários entre disciplinas oferecidas a partir da reestruturação curricular. O "novo" currículo foi marcado pela possibilidade oferecida aos estudantes de cursarem a graduação de Educação Física no turno da manhã ou no turno da tarde. Isso, porém, gerou alterações significativas àqueles estudantes em transição curricular para organização de suas matrículas nos semestres subsequentes, pois, com o reajuste de disciplinas em turnos, algumas disciplinas passaram a colidir e a lotar nos horários de oferecimento, limitando a solicitação de matrícula por parte dos estudantes em transição curricular. Então, restou aos estudantes nesta situação cursarem menos disciplinas por semestre, retardando as etapas que o currículo em vigência exigia. Claramente, sendo outro empecilho que refletiu no adiamento da pretensão de conclusão de curso dos estudantes em transição curricular. Os relatos transcritos a seguir destacam o descontentamento com esta situação. ${ }^{3}$

Que se ofereçam mais turmas.[...] Não colocar disciplinas obrigatórias de um turno no mesmo horário (p.68). Vagas por turmas (melhor elaboração e espaço físico para que ocorram) (p.71). Organização de horários e de cadeiras, ${ }^{*}{ }^{4}$ pois várias cadeiras tiveram o mesmo horário, turmas lotadas, não consegui pegar cadeiras mesmo com bom desempenho no currículo por falta de vagas (p.72).

Assim, identificamos que as primeiras impressões dos estudantes em transição curricular foram de que as mudanças curriculares eram necessárias, mas com a ressalva de que elas deveriam ter sido mais bem divulgadas e ajustadas para quem estava com o curso em andamento durante o processo de reestruturação curricular. A transição curricular gerou desconforto, dúvidas e reajustes nas perspectivas de conclusão de curso para muitos estudantes da ESEFID já no início de 2012, mas este ponto não foi o único aspecto negativo relevante apontado pelos entrevistados do NAU.

\section{Polarizações materializadas no Currículo}

$\mathrm{Na}$ Educação Física há uma clássica polarização na forma de se produzir conhecimento que mobiliza o campo acadêmico em diferentes instâncias, e que se materializa na estruturação dos currículos de formação superior da área. Conforme Edson Manoel e Yara CarvaIho, ${ }^{12}$ esta forma de produção de conhecimento pode ser alocada em três subáreas: a biodinâmica, a sociocultural e a pedagógica. A primeira compreende basicamente disciplinas como bioquímica do exercício, biomecânica, fisiologia do exercício, controle motor, aprendizagem e desenvolvimento motor; a segunda se caracteriza pela abordagem mais vinculada as áreas da sociologia, da antropologia, da história e da filosofia, que influenciam

\footnotetext{
*3: O ordenamento é um procedimento administrativo que rege a distribuição de vagas das disciplinas entre os alunos da graduação que solicitam matrícula nas disciplinas. Ele é baseado em índices que levam em consideração a seriação aconselhada do aluno no currículo, o semestre de ingresso, a média harmônica dos conceitos de aprovação e reprovação nas disciplinas cursadas pelo estudante. Mais informações podem ser
} obtidas no link: http://www.ufrgs.br/prograd/aluno/matricula

*4: "Cadeira" é o termo utilizado pelos estudantes da UFRGS para se referirem à atividade de ensino. 
de modo muito forte os estudos sobre esporte e lazer como fenômenos sociais; e a última está associada a estudos que lidam com a formação de professores, currículos escolares, métodos de ensino, didática e teorias da educação de um modo geral. Em função do maior número de estudos desenvolvidos na subárea biodinâmica, as duas outras subáreas (sociocultural e pedagógica) acabam sendo tratadas como se fossem uma só, até para que possam fazer frente à presença ostensiva dos disciplinas de natureza biodinâmica nos currículos de formação superior em Educação Física. ${ }^{12}$

As ressonâncias desta polarização também aparecem nos relatos dos estudantes em transição curricular. Para alguns, por exemplo, faltam disciplinas das subáreas sociocultural e pedagógica: "Espero que o curso abranja mais áreas sociais, culturais e históricas" (p.60). "Cadeiras obrigatórias de filosofia e português. Devemos valorizar o produto humano, e rever nossa cultura" (p.75). ${ }^{3}$

Outros, no entanto, reivindicaram disciplinas mais afeitas à área biodinâmica: ${ }^{3}$

Achei que esse novo currículo muito mais voltado para as áreas sociais, de lazer e cultura, e não concordo com essa visão de Educação Física, que não faz com que os alunos entendam as áreas fundamentais e de base como as disciplinas biológicas (p.72). Maior ênfase nas cadeiras: Bioquímica, Bioquímica do Exercício, Fisiologia, Fisiologia do Exercício (p.78).

Da mesma forma, o PPC apresenta o currículo organizado em três eixos de formação que apontam à aquisição de habilidades e competências qualificadas de um Licenciado em Educação Física. Esses eixos foram divididos em núcleos de conhecimento, nos quais estão agrupadas as disciplinas do curso. ${ }^{1}$

Um dos eixos se refere ao Eixo da Formação Geral correspondente a duas disciplinas comuns a todos universitários, chamadas de Introdução aos Estudos Universitários I e de Introdução aos Estudos Universitário II (com carga-horária total de 30 horas no curso). O segundo, o Eixo da Formação Específica está organizado em oito núcleos de conhecimento: Campo Profissional (CH total: 15h); Pesquisa em Educação Física ( $\mathrm{CH}$ total: 120h); Estudos Socioculturais (CH total: 180h); Desenvolvimento Humano ( $\mathrm{CH}$ total: 150h); Práticas Corporais Sistematizadas $(\mathrm{CH}$ total: $870 \mathrm{~h}$, sendo 570h obrigatórias); Conhecimentos Biodinâmicos $(\mathrm{CH}$ total: 360h); Exercício Físico e Saúde ( $\mathrm{CH}$ total: 255h) e Estudos do Lazer ( $\mathrm{CH}$ total: 120h). Este eixo se refere às disciplinas que são comuns a todos estudantes do curso de Educação Física. ${ }^{1}$

O terceiro e último eixo diz respeito à Formação Orientada para a Educação Física Escolar, que é composto de quatro núcleos: Fundamentos da Educação Escolar ( $\mathrm{CH}$ total: 150h); Fundamentos da Educação Física na Escola (CH total: 120h); Fundamentos da Educação Inclusiva ( $\mathrm{CH}$ total: 90h) e Práticas Docentes em Educação Física Escolar (CH total: 555h). ${ }^{1}$

Os relatos dos estudantes em transição curricular convergem para a solicitação de ampliação do número de disciplinas dos núcleos de Conhecimentos Biodinâmicos e de Exercício Físico e Saúde. No currículo da Licenciatura em Educação Física, tais núcleos possuem, de fato, menor carga horária ao longo do curso, se comparados à soma das cargas horárias dos núcleos de Estudos Socioculturais, Lazer e Escolar. Isso poderia explicar a lacuna percebida pelos estudantes durante a formação em relação às Ciências Biológicas. Além disso, outro aspecto que pode ser considerado em relação a esse aparente desequilíbrio é que os estudantes que se identificam com os estudos biodinâmicos indicam-no como principal eixo para a formação em geral. Em contraponto, os estudantes que se identificam com as Ciências Humanas (lazer, campo escolar, socioculturais) apontam que essa área deveria receber melhor tratamento ao longo do curso.

Da mesma forma, ao analisarmos exclusivamente o currículo do Bacharelado em Educação Física, a distribuição de carga horária é inversa, ou seja, é muito maior a carga horária da área biodinâmica. A sensação de uma carga horária maior para os conteúdos relacionados à área sociocultural, do lazer e da escola se dá pelo fato de que o ingresso, após 2012, só pode ser feito exclusivamente na Licenciatura em Educação Física. Neste curso, os ingressantes se deparam, desde a primeira até a terceira etapa, com disciplinas ministradas junto à Faculdade de Educação da UFRGS. Não havendo mais ingresso via vestibular no Bacharelado em Educação Física, aqueles estudantes que ingressaram neste curso em período anterior a 2012, via ingresso vestibular, acabaram se tornando um grupo em processo de extinção nas dependências da ESEFID.

Outra polarização que emergiu a partir dos relatos dos estudantes diz respeito à proporção entre a carga horária teórica e prática nas disciplinas. A relação entre teoria e prática no processo de formação superior é indissociável, especialmente em áreas como a Educação Física, eminentemente voltada para o campo da intervenção profissional. Contudo, podemos perceber nos relatos de muitos estudantes uma distinção entre os aspectos teóricos e práticos das disciplinas constantes na grade curricular tomando como referência a maior ou menos ênfase na perspectiva procedimental (saber fazer). Sobre esse tema, o PPC ${ }^{1}$ nos permite verificar quantitativamente como se distribuem as disciplinas consideradas teóricas e as consideradas práticas dentro do currículo. Assim, o currículo apresentou 56 disciplinas obrigatórias na graduação em Licenciatura. Destas, apenas 16 disciplinas estão agrupadas ao Núcleo de Práticas Corporais Sistematizadas. Dentre as 16 disciplinas, 07 são relacionadas a modalidades de esporte, sendo apenas três destas obrigatórias ao longo do curso. As demais tratam de práticas corporais de maneira ampla como, por exemplo: Bases das Práticas Corporais Esportivas ( $\mathrm{CH}: 08 \mathrm{~h})$, Bases das Atividades Aquáticas (CH: 15h) e Bases das Práticas Corporais Sistematizadas ( $\mathrm{CH}$ : 15h). Claramente, o currículo possui predominância teórica, mesmo com carga horária elevada no Núcleo de Práticas Corporais Sistematizadas (570h), a prática como componente curricular se restringe a 400 horas no total da graduação. ${ }^{1}$ Diversas disciplinas estão previstas no currículo para abordar temas das práticas corporais sistematizadas, porém, poucos professores agregam a sua metodologia vivências práticas dos conteúdos ministrados nas disciplinas. O relato de um estudante em transição curricular exemplifica tal situação. ${ }^{3}$ 
Algumas disciplinas não constam um percentua elevado de parte prática. Tínhamos acesso a muita teoria, mas na hora de aplicarmos essa teoria na prática senti muita dificuldade. Entendo que o conteúdo teórico e a prática devem andar juntos, ou seja, o que vemos na teoria imediatamente aplicarmos na prática. Acredito que assim a aprendizagem seria mais rápida e facilitaria muito a vida do acadêmico (p.78).

A predominância teórica no currículo é observada também na grade de disciplinas eletivas oferecidas pelo curso. As disciplinas eletivas são opções que os estudantes possuem para cursar temas de sua preferência em qualquer momento da graduação. São oferecidas no currículo aproximadamente 38 disciplinas eletivas (em 2015), sendo 15 de caráter predominantemente prático. Entretanto, apenas oito destas disciplinas possuem turmas ativas aos estudantes no momento da matrícula, geralmente por falta de corpo docente para assumir as temáticas e a carga horária das disciplinas.

Identificando os relatos dos estudantes em transição curricular, observamos que o descontentamento não se dá apenas com a carga horária de momentos práticos nas disciplinas em relação à carga horária teórica dos conteúdos, mas também se refere à reduzida variedade de práticas corporais oferecidas ao longo da formação acadêmica em Educação Física. As opções no currículo são inferiores à demanda exigida pelo mercado de trabaIho, tanto para licenciados quanto para bacharéis. $O$ que é perceptível na fala dos estudantes quando se referem à questão da "predominância teórica" é a necessidade, por parte dos discentes, de experimentação dos saberes de cunho procedimental, mais associados ao ensino dos fundamentos de determinadas práticas corporais, não restritas ao domínio das questões conceituais sobre tais práticas. Além disso, somando as alternativas reduzidas com a dificuldade dos docentes em relacionar a teoria dos conteúdos com a prática que os estudantes vão encontrar no mercado de trabalho, desdobra-se o segundo aspecto negativo mais citado pelos estudantes em transição curricular: a relação da teoria com a prática profissional. “Embasamento teórico-prático para a vida profissional, ter uma boa formação. Não ter apenas o teórico (p.60). “Ter maior relação prática nas aulas" (p.70). ${ }^{3}$ "Mais integração entres as escolas (Municipal, Estadual e Particular) com a Universidade" (p.71). ${ }^{3}$

Pode-se identificar, assim, que os estudantes consideram que durante a graduação, os conhecimentos se concretizam mais no âmbito teórico e de modo afastado da prática profissional dos futuros docentes. Essa situação poderia estar trazendo dificuldades de estabelecer conexões entre as aprendizagens teóricas e a prática docente nos diferentes espaços profissionais que a Educação Física acontece, pois, conforme Jonas Daniel ${ }^{11}$ o currículo vivido pelos estudantes no contexto pesquisado não é capaz de estruturar os conteúdos de uma forma sequencial, crítica e lógica entre os conhecimentos. Assim, destacam-se relatos de estudantes que consideram disciplinas "desnecessárias" ao longo do curso para sua formação, já que não encontram afinidades entre os conteúdos e as exigências que enfrentam no âmbito profissional: "Algumas cadeiras são desnecessárias, como as da FACED (Faculdade de Educação), pois trata de assuntos que não se encaixam na Educação Física" (p.75). ${ }^{3}$
Para Nunes e Fraga, ${ }^{13}$ que realizaram um estudo sobre os estágios obrigatórios da licenciatura no tempo em que ainda não havia curso de bacharelado em Educação Física na UFRGS, os estudantes sabem da existência de muitos conteúdos, dominam alguns, mas não sabem o que justifica a presença e a disposição de cada um deles no currículo, nem têm "noção de como articulá-los em seus discursos e na prática do ensino" (2006, p.295). Para esses autores, seria necessário pesquisar mais sobre o percurso dos estudantes ao longo da formação inicial, visando discutir de forma mais profunda os conhecimentos que sustentam a prática docente e o estabelecimento de conexões entre a teoria e a prática desde o início dos cursos de licenciatura. ${ }^{13} \mathrm{Em}$ relação a isso, Adroaldo Gaya ${ }^{14}$ diz que há professores nos cursos de Educação Física que se especializaram em determinadas subáreas e que, no entanto, raramente conversam sobre a Educação Física em sua visão mais ampla. Essa característica do corpo docente talvez possa explicar, em parte, os distanciamentos entre as disciplinas, as práticas do mercado de trabalho e o cotidiano dos estudantes, futuros professores de Educação Física. Além disso, talvez também possa explicar mais dois dos principais aspectos negativos que os estudantes relataram: a pouca relação entre as disciplinas do currículo e as superposições de conteúdos encontradas nas disciplinas da graduação, exemplificados nos relatos transcritos abaixo: ${ }^{3}$

Acho que deve haver maior comunicação entre professores para que suas disciplinas se complementem e que conteúdos não sejam repetidos. (2012b, p.67)

Falta ligação e diálogo entre os professores, algumas vezes cada um diz uma coisa diferente, contradiz o outro (...). Melhor seria se eles se unissem para um melhor ensino. (2012b, p.70)

Siqueira ${ }^{15}$ abordou a temática da docência compartilhada na ESEFID/UFRGS. O autor mostrou que o movimento da interdisciplinaridade estava em processo inicial, com docências compartilhadas de forma isoladas, e que talvez os docentes não estivessem devidamente preparados para esta metodologia implantada no novo currículo, ${ }^{15}$ assim, como o relato encontrado no relatório: ${ }^{3}$

Acho que os professores deveriam passar por uma capacitação para compreender e então aderir ao novo currículo, pois muitas disciplinas trocaram de nome, mas não mudaram a didática (metodologia), etc. (2012b, p.69)

Como, então, preparar os estudantes para um trabalho coletivo, multiprofissional e/ou interdisciplinar se o corpo docente responsável pela formação não se encontrar preparado para exercer o ensino compartilhado ao longo da graduação?

\section{CONSIDERACÕES FINAIS}

A partir desse estudo, conseguimos verificar que as mudanças curriculares ocorridas no ano de 2012 nos cursos de Educação Física da UFRGS eram, à época, necessárias, pois os currículos vigentes antes da reestruturação curricular já não contemplavam as expectativas da 
comunidade da ESEFID. Contudo, segundo os estudantes em transição curricular, as alterações foram realizadas em curto tempo, adotadas de uma só vez e de maneira um tanto abrupta, gerando muita informação desencontrada para os estudantes, que se sentiram prejudicados em suas perspectivas de conclusão e trajetória de curso. Por meio dos relatos analisados, identificamos que os estudantes que ingressaram antes da alteração curricular, e que estavam em vias de concluir o curso, apontaram prejuízos a sua formação devido aos reajustes de cargas horárias das disciplinas, às alterações no sequenciamento de disciplinas entre as etapas do curso, às reduzidas opções de práticas corporais sistematizadas e às dificuldades relacionadas ao processo de matrícula nas disciplinas.

Os relatos dos estudantes em transição curricular contidos na documentação do NAU/ESEFID nos permitiram inferir que, aparentemente, nesse período de transição para o "novo" currículo, o que havia sido previsto no $\mathrm{PPC}^{1}$ não se articulava de modo tão forte com o que era efetivamente realizado na prática docente na ESEFID. A documentação consultada mostra que, apesar de o PPC e o currículo terem sido substancialmente alterados, alguns professores seguiram fiéis às estruturas de suas antigas disciplinas. ${ }^{3}$

Para evitar inconveniências, como, por exemplo, o atraso na conclusão do curso por parte dos estudantes, concluímos que seria recomendável para a boa administração do currículo que a implantação de uma nova estrutura curricular venha a ser aplicada apenas às turmas de ingressantes, ou seja, consideramos que seria melhor para qualquer processo de reestruturação de cursos que a figura do "estudante em transição curricular" deixasse de existir.

Os relatos dos estudantes em transição curricular não nos permitem identificar se o posicionamento desse grupo, que ainda não estava vivendo organicamente o "novo" currículo da ESEFID/UFRGS, seria uma crítica ao antigo currículo ou ao currículo implementado em 2012. Além disso, as falas dos estudantes também potencializam outras inquietações, tais como: será que um recém-ingressante em um novo currículo, que cursou muito poucas disciplinas, estaria apto a um posicionamento crítico sobre o "novo" currículo e seu respectivo PPC? Levando em consideração tais questionamentos, imaginamos que essas críticas explicitadas nas falas dos estudantes coletadas pelo NAU podem ser oriundas de experiências obtidas ainda enquanto vinculados ao currículo antigo.

Por meio deste estudo, esperamos provocar maior discussão sobre o percurso do estudante ao longo de sua formação superior em Educação Física, recapitular momentos relevantes da formação dos envolvidos em uma das mais profundas alterações curriculares que os cursos de Educação Física já passaram ao longo de toda a história da UFRGS, bem como promover a reflexão, a partir de leituras e diálogos com discentes e docentes, sobre alguns fatos que auxiliam a construção da identidade dos egressos dos cursos de Educação Física desta instituição septuagenária.

Por fim, é importante ressaltar que no ano de 2015 o NAU esteve novamente realizando um processo de avaliação dos cursos oferecidos pela ESEFID. Acreditamos que estudos futuros poderiam ser efetivados a fim de verificar se as alterações sugeridas pelos estudantes no ano de 2012 foram contempladas e se os aspectos positivos se tornaram mais evidentes do que antes. Sugerimos, ainda, que os documentos de avaliação do NAU da ESEFID/UFRGS venham a ser mais utilizados como fontes de pesquisa, pois são arquivos que contêm informações importantes para formação dos estudantes, para a melhoria do Campus e setores da universidade.

\section{REFERÊNCIAS}

1. Universidade Federal do Rio Grande do Sul. Escola de Educação Física. Projeto Pedagógico do Curso de Licenciatura em Educação Física, 2012.

2. Núcleo de Avaliação da Unidade. Relatório Parcial do Currículo dos Cursos de Dança, Fisioterapia e Educação Física - $3^{a}$ etapa. ESEFID/UFRGS. 2012. Relatório 3.

3. Núcleo de Avaliação da Unidade. Relatório Parcial do Currículo dos Cursos de Dança, Fisioterapia e Educação Física - 4 ${ }^{\text {a }}$ etapa. ESEFID/UFRGS. 2012. Relatório 4.

4. Bardin L. Análise de conteúdo. São Paulo: Edições 70, 2011, 229 p.

5. Cellard A. A Análise Documental. In: Poupart J. et al.. A Pesquisa Qualitativa: enfoques epistemológicos e metodológicos, Petrópolis, RJ: Vozes, 2012 (p.295-316).

6. Sacristán JG. O Currículo: uma reflexão sobre a prática. $3^{\mathrm{a}}$ ed. - Porto Alegre: Artmed, 2000, 352 p.

7. Brugnerotto $F$, Simões R. Caracterização dos currículos de formação profissional em Educação Física: um enfoque sobre saúde. Physis 2009;19(1):149-72.

8. Mendes CL. O campo do currículo e a produção curricular na Educação Física nos anos 90. Arquivos em Movimento 2005;1(2):39-48.

9. Fraga AB, Wachs F, Nunes RV, Bossle CB, Bastos APP, Breunig FF. Alterações Curriculares de uma Escola Septuagenária: um estudo sobre as grades dos cursos de formação superior em Educação Física da ESEF/UFRGS. Revista Movimento 2010;16(esp):61-95.

10. Brasil. Lei $n^{\circ} 9.696$ de 1 de setembro de 1998. Dispõe sobre a regulamentação da Profissão de Educação Física e cria os respectivos Conselho Federal e Conselhos Regionais de Educação Física. Brasília: Ministério da Educação, 1998.

11. Daniel JV. O curso de licenciatura em educação física na UFRGS: a voz discente. 2009. Trabalho de Conclusão de Curso - Educação Física. Escola de Educação Física, Fisioterapia e Dança/UFRGS. Porto Alegre, 2009.

12. Manoel EJ, Carvalho YMC. Pós-Graduação na Educação Física brasileira: a atração (fatal) para a biodinâmica. Educação e Pesquisa 2011;7(2):389-406.

13. Nunes RV, Fraga AB. "Alinhamento Astral": o estágio docente na formação do licenciado em Educação Física na ESEF/UFRGS. Pensar a Prática. 2006;9(2):297-311.

14. Gaya A. Educação Física: a vertente pedagógica da cultura corporal do movimento. 55f. Monografia. Educação Física. Escola de Educação Física, Fisioterapia e Dança/UFRGS. Porto Alegre, 2009.

15. Siqueira CFR. Concepções sobre o processo de ensino e aprendizagem da educação física: o caso da docência compartilhada nas aulas do bacharelado da ESEF/UFRGS. 2014, p.43. Trabalho de Conclusão de Curso - Educação Física. Escola de Educação Física, Fisioterapia e Dança/ UFRGS. Porto Alegre, 2014.

Como citar: LIMANA, Priscila Furtado; MACHADO, Eduardo Pinto; FRAGA, Alex Branco. A implantação dos currículos de Educação Física da UFRGS em 2012: uma visão dos estudantes em transição curricular. Cinergis, Santa Cruz do Sul, v. 17 , n. 1, mar. 2016. ISSN 2177-4005. Disponível em: <https://online.unisc.br/seer/index.php/cinergis/article/view/7356> Acesso em: . doi:http://dx.doi.org/10.17058/cinergis.v17i1.7356. 